\title{
Low Anterior Resection Syndrome
}

National Cancer Institute

\section{Source}

National Cancer Institute. Low Anterior Resection Syndrome. NCI Thesaurus. Code C160144.

A collection of symptoms following removal of part or all of the rectum that may include frequency or urgency of stools, numerous bowel movements over a few hours, fecal incontinence, constipation alternating with numerous bowel movements, and/or increased intestinal gas. 